\title{
Feeding of HIV-exposed children in a city in south of Brazil: family capability, clinical and social conditions
}

\author{
Marília Alessandra Bick 1 \\ https://orcid.org/0000-0002-8744-7790 \\ Paulo Sergio Ceretta 2 \\ iD https://orcid.org/0000-0001-8264-0439 \\ Cristiane Cardoso de Paula 3 \\ https://orcid.org/0000-0003-4122-5161
}

\begin{abstract}
1 Grupo de Pesquisa Cuidado à Saúde das Pessoas, Famílias e Sociedade. Universidade Federal de Santa Maria. Santa Maria, RS, Brasil
2 Centro de Ciências Sociais e Humanas. Universidade Federal de Santa Maria. Santa Maria, RS, Brasil.

3 Grupo de Pesquisa Cuidado à Saúde das Pessoas, Famílias e Sociedade. Departamento de Enfermagem. Centro de Ciências da Saúde. Universidade Federal de Santa Maria. Av. Roraima, $\mathrm{n}^{\circ}$ 1000, Centro de Ciências da Saúde, prédio 26, $3^{\circ}$ andar, sala 1336, Bairro Camobi. Santa Maria, RS, Brasil. CEP: 97105-900. E-mail: cris_depaula1@hotmail.com.
\end{abstract}

\begin{abstract}
Objectives: to evaluate the association between the sociodemographic and clinical aspects of the caregiver and the child, the family's ability to prepare and administer milk and complementary feeding of children exposed to HIV.

Methods: cross-sectional study performed with 72 caregivers, in Brazil, through the tool of sociodemographic and clinical characterization of the caregiver and the Capability to Care for HIV-Exposed Children Assessment Scale.

Results: there was a high capability to feed (76.6\%), both for milk (85.0\%) and complementary (65\%) feeding. For the milk feeding, accessing the health unit in any situation $(p=0.003)$, having other child exposed to HIV $(p=0.013)$, maintaining the follow-up in the health service $(p=0.048)$ and not consuming alcohol $(p=0.045)$ influenced on the higher probability of the caregiver to present high capability, while residing in the peri-urban area $(p=0.002)$ indicated moderate capability. For the complementary feeding, the higher the schooling $(p=0.025)$, the number of appointments scheduled for the child $(p=0.045)$ and the child being followed up in the health service $(p=0.035)$, the higher the probability of obtaining high capability.

Conclusions: the exposure of social and clinical factors of caregivers influences the ability to feed. To ensure adequate nutrition, it is necessary for the health services to be able to consider the geo-socio-cultural characteristics of families in the elaboration of guidelines. Key words HIV, Infectious disease transmission, Family, Infant nutrition
\end{abstract}

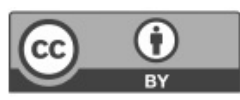




\section{Introduction}

Brazil is considered a worldwide reference in the control of the HIV epidemic, due to the quality of public policies and universal and free access to prophylaxis and treatment of infection. In the case of vertical transmission (VT), when the prophylactic measures are applied, rates are lower than $2 \% .{ }^{1}$ These measures consist of a quick test for all pregnant women, antiretroviral therapy (ART) and specialized monitoring. The selection of the childbirth route, prophylaxis until umbilical cord clamping and inhibition of breastfeeding, in addition to care for the newborn, with removal of maternal secretions, initiation of ART in the delivery room for up to 28 days and use of prophylactic antibiotic therapy for pneumonia up to the fourth month and free supply of infant formula. ${ }^{2}$

In spite of prenatal failures, ${ }^{3}$ the rate of detection of AIDS in children under 5, an indicator used to monitor HIV VT in Brazil, decreased by $42.7 \%$ between 2006 and 2015.1 The practice of breastfeeding accounts for 30 to $50 \%$ of cases of VT and reduces the positive impact of the prevention interventions performed during pregnancy and delivery. Therefore, children fed exclusively with infant formula have a lower risk of acquiring HIV after birth. ${ }^{4}$ However, when such food is not properly prepared, that is, with correct dilution in boiled and filtered water and with hygienization of utensils and hands, the risk of increased child malnutrition, growth failure, morbidity and mortality from infectious diseases is factual. 5 In view of this, in places deprived of resources, where sanitary conditions are precarious and access to infant formula is restricted by the high cost, as in the case of Africa, there is a predominance of exclusive breastfeeding. 6

While breastfeeding brings the temerity of transmitting HIV, not breastfeeding can bring significant risks to the child's health, such as increased infant morbidity and mortality, including malnutrition. In order to enable growth, maturation of bodily functions and prevention of nutritional disorders, the feeding of non-breastfed children should provide the necessary substrates, as well as being accessible, acceptable, viable, safe and sustainable.7,8 Therefore, it is imperative to consider the social, financial and environmental conditions of the family that can reflect in children's feeding practices. ${ }^{7}$

Children depend on a caregiver for adequate growth and development. 9 In HIV exposure, this care is performed mainly by the infected mother or other members of the household, so it is necessary to consider the different family settings in health care. ${ }^{10}$ The professional must provide them with information that improve the skills of care in the home environment, minimizing difficulties. ${ }^{11}$

Nutritional deficiencies are known to worsen the evolution of HIV infection, and therefore accentuate unfavorable clinical outcomes. The main consequences are incomplete suppression of viral RNA, reduction of CD4 lymphocytes over time, loss of body mass, decreased quality of life, increased opportunistic infections, hospitalizations and mortality. In families with at least one adult with $\mathrm{HIV}$, these consequences perpetuate the effects of poverty and social exclusion, harming the income generation, which may affect the ability of caregivers to adhere to food safety recommendations. ${ }^{9}$

Therefore, there is a need for researches that address the topic of food for children exposed to HIV who should not receive breastfeeding. The purpose of this article was to evaluate whether the sociodemographic and clinical aspects of the caregiver and the child are related to the family capability to prepare and administer the milk and complementary feeding of children exposed to HIV.

\section{Methods}

Cross-sectional study, developed from February 2016 to March 2017, in a city located in the centralwestern region of the state of Rio Grande do Sul, Brazil. The research scenario was the specialized service of the Santa Maria University Hospital, considered as a regional reference for the care of HIV-infected people. This hospital is an integrating organ of the Federal University of Santa Maria and has its actions focused on teaching, research and healthcare.

The sample was defined by convenience and comprised 72 children exposed to HIV, aged from zero to 18 months, born between August 2014 and December 2016, and their main family caregivers. All the children who accessed the health service during the period of data collection were included. As exclusion criteria, were disregarded children with loss of follow-up. Access to information from the mother-child binomial occurred on the days of appointment in the pediatric or adult infectious diseases clinic of the reference service and/or by telephone contact. For data collection, a research instrument for the sociodemographic and clinical characterization of the caregiver was used for the clinical and dietary characterization of the child, as well as the Capability to Care for HIV-Exposed Children Assessment Scale.12 The scale was constructed and validated in Brazil,12,13 and is 
recommended for accessing information about the care provided to children exposed to HIV.

The scale evaluates the health care for children born exposed to HIV and is composed of five dimensions and 52 questions. In this article, the dimensions II (capability to prepare and administer milk feeding) and III (complementary feeding), composed of 17 and 22 questions, respectively, totaled 39 questions used in this study. The answers to these questions are: never, rarely, sometimes, often or always. Levels of caring ability are characterized as low (dimension II: score between 17 to 40 and dimension III: score between 22 to 51 ), moderate (dimension II: score between 41 to 64 and dimension III: score between 52 to 81 ) and high (dimension II: score between 65 to 88 and dimension III: score between 82 to 110 ), and for overall feeding capability (sum of dimensions II and III), as low (score between 39 to 91 ), moderate (score between 92 to 145) and high (score between 146 to 198).

For the analysis, the database was typed and organized in the EXCEL software, and was exported to the Statistical Package for Social Sciences (SPSS) software version 13.0. The variables were described by absolute and relative distributions. To verify the association between the characteristics of the caregiver, child and type of milk feeding (infant formula and/or cow's milk) with the ability to feed, the Pearson's chi-square test and Fisher's exact test were used considering a significance level of $p<0.05$.

To investigate the existence of associations between independent variables and the ability to feed, a Poisson regression model with robust variance was used. A bivariate analysis was performed to evaluate possible associations between the sociodemographic and clinical variables (independent variables) and the ability to feed (dependent variable). In this procedure, a probability inferior to $5 \%$ was considered as a significant statistic level for the selection in the multiple Poisson regression model. However, none of the variables presented statistically significant association with $p<0.20$ in the multiple regression analysis.

This project was approved by the Research Ethics Committee of the Federal University of Santa Maria.

\section{Results}

The caregiver population is characterized by women (97.2\%), aged between 28 and 37 years $(50 \%)$, living in a stable union (75\%), with high school educational level $(50 \%)$, which are unemployed $(65.3 \%)$ and have a family income of 1 to 2 minimum wages (44.4\%). As for demographic characteristics, most of them live in the city of Santa Maria $(77.8 \%)$, in urban areas $(83.3 \%)$ and have between 2 and 4 children (56.9\%). In the clinical characterization, HIV-infected mothers (95.8\%), who acquired the virus through sexual transmission (56.9\%), were diagnosed between 1 and 5 years $(41.7 \%)$, were in ongoing treatment $(87.5 \%)$ and had no health problems $(84.7 \%)$ prevailed.

The characterization of the type of milk feeding indicates the predominance of infant formula in $58.3 \%(\mathrm{n}=42)$, followed by cow's milk in $37.5 \%$ $(\mathrm{n}=27)$. The adequate frequency of feeding administration was of $63.9 \%(n=46)$ for milk feeding and $31.6 \%(n=19)$ for complementary feeding. Among the children who were not receiving complementary feeding (16.7\%), two were over than six months old. Among those who received human milk (8.3\%), three were exposed in one occasion to cross-nursing by a family member with an unknown serological condition, and the others, in one occasion, to their own mother's milk (Table 1).

The overall capability assessment was performed only for caregivers of children who were receiving complementary milk supplementation $(n=60)$, with a prevalence of high capability $(76.6 \%)$. Regarding milk feeding, $97.2 \%(n=70)$ of the caregivers stated that they always reconstituted the formula as recommended by health professionals. Administration of the milk feeding until two hours after preparation was always performed by $50 \%(n=36)$ of the caregivers. When leaving home, $65.3 \%(\mathrm{n}=47)$ always offered boiled, filtered or mineral water to the child, and $80.5 \%(n=58)$ adopted this care to reconstitute the infant formula/cow's milk only at the time of consumption. Additionally, $79.6 \%(\mathrm{n}=57)$ sanitized their hands to prepare the milk feeding.

Regarding the preparation of complementary food, $13.2 \%$ of the caregivers always used a blender, $85 \%$ sanitized their hands before preparation and $23.2 \%$ sanitized fruits and vegetables with sodium hypochlorite. In addition, $15 \%$ stated that the food left on the plate or cup was offered to the child later, $13.2 \%$ added sugar to the complementary food and $10 \%$ offered ultra-processed foods (Table 2).

The assessment of the ability to prepare and administer milk feeding was significantly associated with the social characteristics of the caregiver: the ones who lived in rural areas $(p=0.002)$ and the ones who did not consume alcohol $(p=0.045)$ presented high capability. The high capability to prepare and administer complementary feeding was significantly associated with higher household income $(p=0.028)$. Moreover, when compared to 
the others, caregivers who reported no income presented moderate ability (Table 3).

Regarding the variables of caregivers, having other children exposed to HIV had statistical significance $(p=0.013)$ for the high capability to prepare and administer milk feeding (Table 4). Maintaining the health follow-up of the child presented statistical significance $(p=0.035)$ for the high capability of the complementary feeding. In addition, having access to a health service near the residence in any situation $(p=0.003)$ presented statistical significance in both dimensions.

The logistic regression analysis was performed to verify the association between clinical and social variables with the dependent variable. The variables associated with the ability to prepare and administer milk were submitted to gross and adjusted regression, and the respective $95 \%$ confidence intervals were estimated (Table 5). For complementary feeding, these values did not present statistical significance.

\section{Discussion}

The social factors (geographical residence zone, schooling, income and alcohol consumption) and clinical factors (maintaining health follow-up and having other children exposed to HIV) of caregivers influence the capability to feed the child exposed to HIV. As for the variables of healthcare, accessing a basic health unit when necessary in any situation, and keeping the child's follow-up in the health service both positively influence the level of feeding capability.

The ability to prepare and administer milk feeding was high for $85 \%(\mathrm{n}=61)$ and moderate for $15 \%(n=11)$ of the caregivers. As for dimension III, complementary feeding was found to be high for $65 \%(\mathrm{n}=39)$, moderate for $33.4 \%(\mathrm{n}=20)$ and low for $1.6 \%(\mathrm{n}=1)$.

We observed that there is a decrease in the capability score between dimensions, which indicates the need for investment in promotion and support of milk feeding and continuity of orientation, enabling the families to have the necessary knowledge to introduce complementary feeding in timely timing, quantity and quality. Similar with the capability evaluated in northeastern Brazil, which was high for preparing and administering milk $(86 \%)$ and moderate for complementary feeding (44.4\%). $13 \mathrm{In}$ another period, it was confirmed that the capability to prepare and administer milk was higher when compared (high for $86 \%$ ) to the complementary (moderate for $45.7 \%$ and high for $48.5 \%$ ). ${ }^{14}$

The occurrence of breastfeeding and crossnursing reveals the difficulty encountered by care-

Table 1

Characterization $(n=72)$ of feeding offered to children vertically exposed to HIV, in a city in the interior of southern Brazil, 2017.

\begin{tabular}{lcc}
\hline Variables & $\mathbf{N}=\mathbf{7 2}$ & $\%$ \\
\hline Exposure to breast milk. & 6 & 8.3 \\
Yes & 66 & 91.7 \\
No & 27 & 37.5 \\
Type of milk feeding & 42 & 58.3 \\
Cow's milk & 3 & 4.2 \\
Infant formula & & \\
Cow's milk and infant formula & 46 & 63.9 \\
Frequency of milk feeding* & 26 & 36.1 \\
Adequate & & \\
Inadequate & 60 & 83.3 \\
Complementary feeding & 12 & 16.7 \\
Yes & & 31.6 \\
No & 19 & 68.4 \\
Frequency of complementary feeding*+ & 41 & \\
Adequatete & & \\
Inadequate & & \\
\hline
\end{tabular}

*Rated according to ministerial recommendations. $15+n=60$. 
Table 2

Aspects related to the preparation of milk feeding $(n=72)$ and complementary feeding for children $(n=60)$ born exposed to HIV. Santa Maria, 2017.

Variables

Often

$\begin{array}{ccccccccc}\mathrm{n} & \% & \mathrm{n} & \% & \mathrm{n} & \% & \mathrm{n} & \% & \mathrm{n}\end{array}$

Aspects related to milk feeding $(n=72)$

Child was breastfed by another woman*

Dilutes the milk as recommended for the age or by professional guidance

offers milk according to age or professional recommendation

Shares the child's milk can with others*

When the child does not drink the milk immediately after preparation, uses it within two hours

When leaving the house, takes boiled, filtered or mineral water to prepare the milk when

feeding the child

When leaving the house, take boiled, filtered or mineral water to give to the child

Before preparing the milk, observes the conditions of the can and the expiry date

Before preparing the milk, washes hands with soap and water

Aspects related to complementary feeding $(n=60)$

Introduces food as recommended for the age or by professional guidance

Offers meals according to age or professional guidance

Adds sugar to the food*

Offers ultra-processed foods*

Liquefies the baby food*

Offers scraped or mashed fruits

Reuses the leftover food to offer later*

Sanitizes fruits and vegetables under running water and sodium hypochlorite

Washes hands with soap and water before preparation

$\begin{array}{cccccccccc}69 & 95.8 & 1 & 1.4 & 2 & 2.8 & - & - & - & - \\ 2 & 2.8 & - & - & - & - & - & - & 70 & 97.2 \\ 5 & 6.9 & - & - & 9 & 12.5 & 1 & 1.4 & 57 & 79.2 \\ 69 & 95.8 & - & - & 1 & 1.4 & - & - & 2 & 2.8 \\ 25 & 34.7 & 2 & 2.8 & 7 & 9.7 & 2 & 2.8 & 36 & 50 \\ & & & & & & & & & \\ 7 & 9.7 & 6 & 8.4 & - & - & 1 & 1.4 & 58 & 80.5 \\ 17 & 23.6 & - & - & 5 & 6.9 & 3 & 4.2 & 47 & 65.3 \\ 6 & 8.4 & 3 & 4.2 & - & - & - & - & 63 & 87.4 \\ 2 & 2.4 & 3 & 4.2 & 10 & 14 & - & - & 57 & 79.6 \\ & & & & & & & & & \\ & & & & & & & & & \\ 13 & 21.6 & 2 & 3.2 & 5 & 8.3 & 1 & 1.6 & 39 & 65.3 \\ 13 & 21.6 & 2 & 3.2 & 6 & 10.0 & 5 & 8.3 & 34 & 56.9 \\ 35 & 58.6 & 6 & 10.0 & 9 & 15.0 & 2 & 3.2 & 8 & 13.2 \\ 25 & 41.6 & 5 & 8.3 & 21 & 35.1 & 3 & 5.0 & 6 & 10.0 \\ 38 & 63.6 & 3 & 5.0 & 10 & 16.6 & 1 & 1.6 & 8 & 13.2 \\ 14 & 23.2 & 1 & 1.6 & 10 & 16.6 & 3 & 5.0 & 32 & 53.6 \\ 46 & 76.8 & - & - & 3 & 5.0 & 2 & 3.2 & 9 & 15.0 \\ 44 & 73.6 & 1 & 1.6 & 1 & 1.6 & - & - & 14 & 23.2 \\ - & - & - & - & 8 & 13.2 & 1 & 1.6 & 51 & 85.0 \\ & & & & & & & & & \end{array}$

*considered for the sum with inverted scores. 
Table 3

Distribution of the sociodemographic variables of the caregiver and levels of capability to prepare and administer infant formula and complementary feeding. Santa Maria, 2017.

\begin{tabular}{|c|c|c|c|c|c|c|c|c|c|c|}
\hline \multirow[t]{3}{*}{$\begin{array}{l}\text { Socioeconomic variables } \\
\text { of the caregiver }\end{array}$} & \multicolumn{4}{|c|}{$\begin{array}{l}\text { Capability to prepare and administer } \\
\text { the milk feeding (dimension II) }\end{array}$} & \multirow[t]{3}{*}{$p$} & \multicolumn{4}{|c|}{$\begin{array}{l}\text { Capability to prepare and } \\
\text { administer complementary } \\
\text { feeding (dimension III) }\end{array}$} & \multirow[t]{3}{*}{$p$} \\
\hline & \multicolumn{2}{|c|}{ Low / Moderate } & \multicolumn{2}{|c|}{ High } & & \multicolumn{2}{|c|}{ Low / Moderate } & \multicolumn{2}{|c|}{ High } & \\
\hline & $\mathrm{n}$ & $\%$ & $\mathrm{n}$ & $\%$ & & $\mathrm{n}$ & $\%$ & $\mathrm{n}$ & $\%$ & \\
\hline Age group (years) & & & & & 0.941 & & & & & 0.362 \\
\hline $18-27$ & 4 & 14.3 & 24 & 85.7 & & 11 & 47.8 & 12 & 52.2 & \\
\hline $28-37$ & 6 & 16.7 & 30 & 83.3 & & 9 & 29.0 & 22 & 71.0 & \\
\hline $38-47$ & 1 & 12.5 & 7 & 87.5 & & 3 & 50.0 & 3 & 50.0 & \\
\hline Gender & & & & & 0.716 * & & & & & 0.573 \\
\hline Male & 0 & - & 2 & 100.0 & & 0 & - & 2 & 100.0 & \\
\hline Female & 11 & 15.7 & 59 & 84.3 & & 23 & 39.6 & 35 & 60.4 & \\
\hline Marital Status & & & & & 0.809 & & & & & 0.304 \\
\hline Stable Union & 9 & 16.7 & 45 & 83.3 & & 15 & 34.1 & 29 & 65.9 & \\
\hline Single & 2 & 11.8 & 15 & 88.2 & & 8 & 53.3 & 7 & 46.7 & \\
\hline Divorced & 0 & - & 1 & 100.0 & & 0 & - & 1 & 100.0 & \\
\hline Education Level & & & & & 0.141 & & & & & 0.169 \\
\hline 1 st- 4 th grade & 1 & 4.8 & 20 & 95.2 & & 5 & 26.3 & 14 & 73.7 & \\
\hline $5^{\text {th }}-8^{\text {th }}$ grade & 0 & - & 7 & 100.0 & & 0 & - & 6 & 100.0 & \\
\hline High school & 7 & 19.4 & 29 & 80.6 & & 12 & 44.4 & 15 & 55.6 & \\
\hline College & 2 & 33.3 & 2 & 33.3 & & 3 & 50.0 & 3 & 50.0 & \\
\hline No education & 1 & 50.0 & 1 & 50.0 & & 2 & 100.0 & 0 & - & \\
\hline Family income & & & & & 0.830 & & & & & 0.028 \\
\hline Nothing & 1 & 14.3 & 6 & 85.7 & & 3 & 60.0 & 2 & 40.0 & \\
\hline$<1$ minimum wage & 1 & 7.7 & 12 & 92.3 & & 2 & 16.7 & 10 & 83.3 & \\
\hline 1-2 minimum wages & 6 & 18.8 & 26 & 81.3 & & 8 & 33.3 & 16 & 66.7 & \\
\hline$>2$ minimum wages & 3 & 15.0 & 17 & 85.0 & & 9 & 47.4 & 10 & 52.6 & \\
\hline Area of residence & & & & & 0.002 & & & & & 0.345 \\
\hline Urban & 9 & 15.0 & 51 & 85.0 & & 19 & 38.0 & 31 & 62.0 & \\
\hline Rural & 0 & - & 10 & 100.0 & & 1 & 11.1 & 8 & 88.9 & \\
\hline Peri-urban & 2 & 100.0 & 0 & - & & 1 & 100.0 & 0 & - & \\
\hline Employment & & & & & 0.378 & & & & & 0.965 \\
\hline Registered job & 2 & 13.3 & 13 & 86.7 & & 5 & 41.7 & 7 & 58.3 & \\
\hline Unregistered job & 3 & 30.0 & 7 & 70.0 & & 3 & 37.5 & 5 & 62.5 & \\
\hline Unemployed & 6 & 12.8 & 41 & 87.2 & & 14 & 35.0 & 26 & 65.0 & \\
\hline Use of alcohol & & & & & $0.045^{*}$ & & & & & 0.178 \\
\hline Yes & 7 & 26.9 & 19 & 73.1 & & 9 & 50.0 & 9 & 50.0 & \\
\hline No & 4 & 8.7 & 42 & 91.3 & & 13 & 31.0 & 29 & 69.0 & \\
\hline Use of drugs & & & & & 0.059 * & & & & & 0.870 \\
\hline Yes & 2 & 66.7 & 1 & 33.3 & & 2 & 66.7 & 1 & 33.3 & \\
\hline No & 9 & 13.0 & 60 & 67.0 & & 20 & 35.1 & 37 & 64.9 & \\
\hline
\end{tabular}

* Fisher's exact test. 
Distribution of the clinical variables of the caregiver, of the care of the exposed child and the level of capability to prepare and administer the milk and complementary feeding. Santa Maria, $2017(n=72)$.

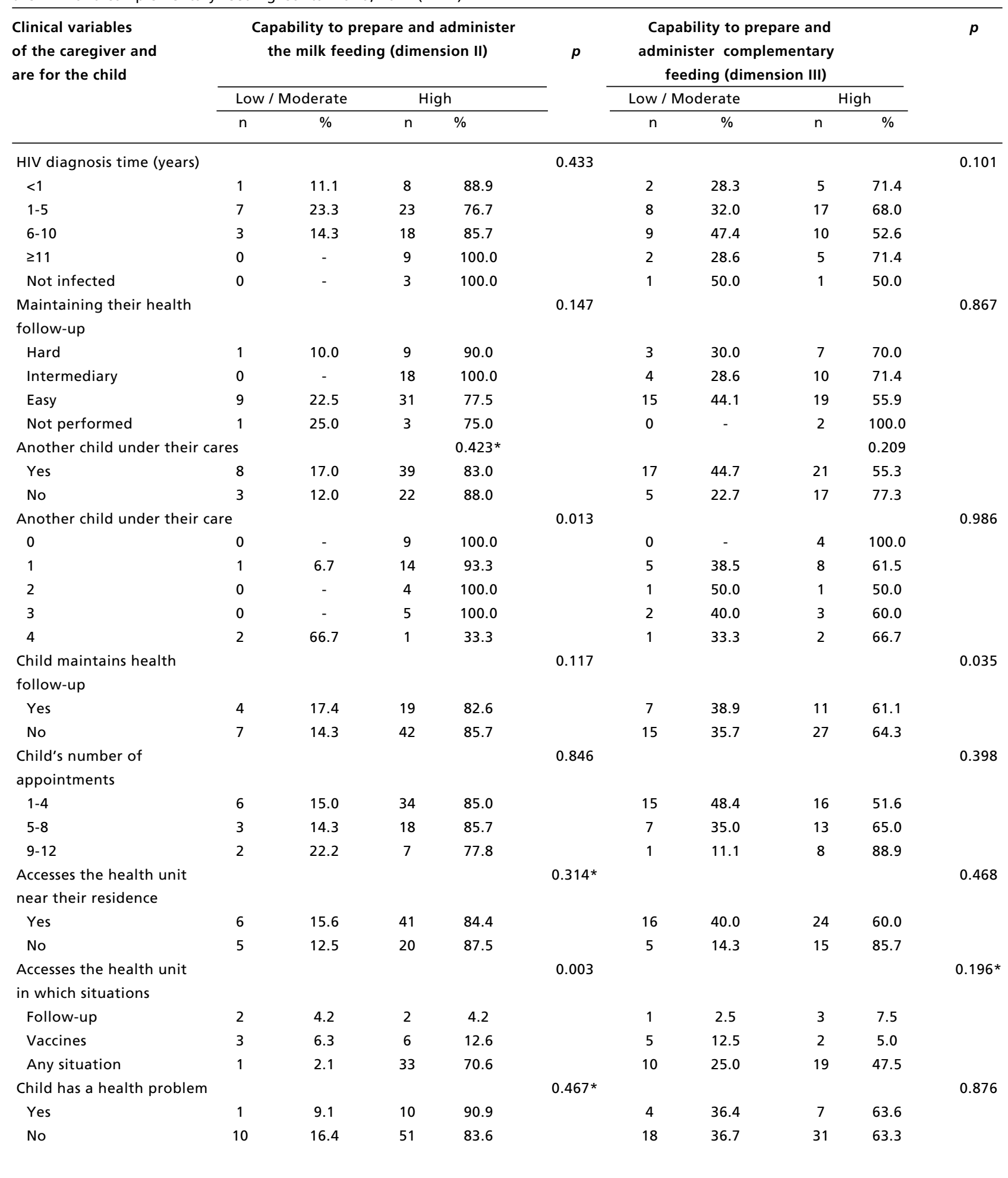

\footnotetext{
* Teste exato de Fisher.
} 
Prevalence and gross ratios adjusted to variables associated with the capability to prepare and administer milk feeding. Santa Maria, $2017(n=72)$.

\begin{tabular}{|c|c|c|c|}
\hline Variables & Gross PR & Adjusted PR & $p^{*}$ \\
\hline \multicolumn{4}{|l|}{ Marital status } \\
\hline Stable Union & $0.83(0.74-0.93)$ & $0.77(0.63-0.93)$ & 0.010 \\
\hline Single & $0.88(0.74-1.05)$ & $0.75(0.54-1.02)$ & 0.075 \\
\hline Divorced & 1 & - & - \\
\hline \multicolumn{4}{|c|}{ HIV Diagnosis Time (years) } \\
\hline$<1$ & $0.88(0.70-1.12)$ & $0.85(0.64-1.13)$ & 0.285 \\
\hline $1-5$ & $0.76(0.62-0.93)$ & $0.72(0.54-0.94)$ & 0.018 \\
\hline $6-10$ & $0.85(0.72-1.02)$ & $0.82(0.67-1.00)$ & 0.059 \\
\hline$\geq 11$ & $1.00(0.00-0.00)$ & $0.97(0.86-1.10)$ & 0.671 \\
\hline Does not have & 1 & - & - \\
\hline \multicolumn{4}{|c|}{ How it is to maintain the child's health follow-up } \\
\hline Not performed & $1.22(1.06-1.40)$ & $1.31(1.00-1.71)$ & 0.044 \\
\hline Hard & $1.03(0.78-1.35)$ & $1.03(0.78-1.36)$ & 0.793 \\
\hline Intermediary & $1.12(0.91-1.39)$ & $1.11(0.89-1.39)$ & 0.313 \\
\hline Easy & 1 & - & - \\
\hline \multicolumn{4}{|c|}{ Accesses the health unit near their residence } \\
\hline Yes & $1.11(0.87-1.41)$ & $1.81(0.91-1.52)$ & 0.204 \\
\hline No & 1 & - & - \\
\hline
\end{tabular}

$\mathrm{PR}=$ Prevalence ratio.

givers in understanding the recommendations of prophylaxis of VT. In the northeastern region of Brazil, mothers with lower levels of schooling presented greater adherence to the recommendation of not breastfeeding (80.8\%). ${ }^{15}$

In situations where breastfeeding can cause harm to a child's health, such as in the case of HIVinfected mothers, this practice is contraindicated. For this reason, it is fundamental that breast-milk substitutes are managed with food safety and security to promote adequate growth of children. ${ }^{8}$ In Brazil, the integral and free supply of milk formula to replace breast milk is guaranteed by a federal law, at least until the sixth month of life. 2,16

In the city researched, the supply of milk formula is maintained beyond the six-month period, subsidized by the municipal health department, until the child reaches 12 months of age. We recognize that this intersectoral articulation for the continuity of the milk formula supply is a social aspect that positively influences the family capability to feed the children exposed to HIV.

The reconstitution of the milk formula should be adequate to the nutritional needs of the child, consi- dering that when diluted in excess it can lead to malnutrition and when too concentrated it can cause dehydration. The frequency and volume of supply must meet the physiological needs, and the hygiene conditions must guarantee the absence of food contamination. Thus, to ensure the attention for caregivers, it is necessary to consider aspects related to best feeding practices during the follow-up of children in health services. ${ }^{6}$ Such caregivers show difficulties regarding the preparation and adequate frequency of milk and complementary feeding to the children. ${ }^{14}$ A study in southern Brazil questioned the mothers about the preparation of the formula, indicating that only $31.8 \%$ of them were advised on dilution and adequate supply during the hospital discharge, and the others received guidance in the specialized service for HIV (53.9\%) and in primary health care $(4.3 \%) .{ }^{5}$ In this evaluation, the feeding practices were inadequate for $31.3 \%$ of the mothers, who added thickeners (sugar and flour) $(19.5 \%)$ and mucilages (rice water or oats) $(18.1 \%)$ to the infants' food. 5

Due to the lack of standardization of the orientation in the services, the caregivers' difficulty of 
understanding triggered inadequate care practices for these children, mainly related to the administration of medications and to the milk or complementary feeding. There is a recommendation that the particularities of families should be considered in order to guarantee the efficacy of the prevention of VT.14,17

The caregivers $(65.3 \%)$ performed the introduction of complementary feeding according to the professionals' orientation. Five of them reported that they had not received orientation, and therefore had initiated complementary feeding prematurely. Early introduction of food does not provide benefits to the child's health and increases the risk of infections, diarrhea and malnutrition. ${ }^{6}$ Among the children who did not receive complementary feeding $(16.7 \%)$, two were more than six months old. Late introduction results in nutrient deficiency, which may lead to anemia, diabetes, obesity, hypertension, among other nutritional disorders. 18

We recognize that counseling by professionals is another social aspect that positively influences the family's capability to feed children exposed to HIV. Guidance can be considered a protective factor for food and nutritional security and, consequently, can avoid the resulting morbidities.

Caregivers reported that they offer the meals according to the age and frequency recommended by health professionals, both for milk $(79.2 \%)$ and complementary feeding $(56.9 \%)$. However, when the supply frequency was compared to the ministerial recommendation, $1863.9 \%(n=46)$ of the children were receiving the appropriate frequency of milk feeding and $31.6 \%(n=19)$ were receiving the appropriate frequency of complementary feeding. The inadequate frequency of milk feeding occurred mainly due to oversupply, which may indicate the incorrect dilution of infant formula or cow's milk. Similar results showed the late introduction of food to $15.5 \%$ of children in the northeastern region of Brazil, and among those who received complementary foods, 55\% had inadequate food intake. 14

In a study conducted in Tanzania, the food introduction was performed between the third and fifth month, and the main food offered to the children was milk porridge. The family's food supply began around the sixth month. In addition, the foods most consumed by children in the mentioned study were cow's milk with added sugar or water, powdered milk and industrialized juice. 19 The addition of sugar $(41.4 \%)$ and the offer of ultra-processed foods (sodas, candies and snacks) $(58.4 \%)$ were in disagreement with the ministerial nutritional recommendation for children under two years old.18 For most children, food consisted of fruits, dairy bevera- ges, processed juices, porridge, bread, biscuits and soup (vegetables, tubers, cereals and meat stock). In a study carried out in the State of Piauí, also in the northeastern region of Brazil, a similar practice was observed, whose main foods offered to the children consisted of porridge, homemade or industrialized baby food, fruits, biscuits, snacks, instant noodles and rice. ${ }^{20}$

We recognize that the early supply of nonrecommended foods, such as industrialized and sugar-rich foods, can be influenced by the family's eating habits. For this reason, educational actions on food and nutrition are necessary to promote adequate and healthy nutrition for both HIV-exposed children and their families.

Poor hand hygiene before food preparation $(14.8 \%)$, inadequate hygienic-sanitary food care (73.6\%) and offering children leftovers (23.2\%) are unsatisfactory practices that reinforce the caregivers' lack of access to health recommendations.

We emphasize that, during the food introduction phase, the attention to hygiene and care practices during food preparation and storage is crucial. Such practices, when inadequate, can contribute to food microbiological contamination and the occurrence of foodborne infections. The risk of a child acquiring foodborne illnesses is increased by the immaturity of their immune system, and can be aggravated by the condition of exposure to HIV, extending health damages. Therefore, it is worth highlighting the role of the nutritionist in transmitting knowledge about food hygiene practices, guiding caregivers and promoting healthy infant feeding. 18

The greater ability of caregivers to prepare and administer milk feeding in rural areas may indicate less exposure to the promotion of ultra-processed foods, even by the media, as well as a greater supply of fresh food at home and at school. A divergent study conducted in a rural area of South Africa indicated the occurrence of inadequate milk feeding practices, including incorrect formula dilution and early introduction of complementary feeding, despite the presence of a continued health education program in the area. 21

Additionally, the fact that the caregivers did not consume alcohol has been associated to high capability to prepare and administer milk feeding. Alcohol consumption interferes with quality of life and is related to low adherence to ART, as well as to the worsening of the clinical picture. The "gender" variable shows that women with alcohol consumption problems are prone to lower adherence when compared to men. 22 Considering that caregivers of exposed children are mostly women, it is relevant to 
note that such exposure to alcohol consumption and decreased adherence to ART increases the risk of diseases and decreases the ability to feed children in the first months of life. Even in situations of illness of the main caregiver, the family remains the foundation of the child's well-being. 26

In the present study, a higher family income is associated with greater ability to prepare and administer complementary feeding. A study conducted in a city in the state of Paraná, which evaluated the monthly cost of food per household, related an average expense of R $\$ 400.00$ to the food insecurity of $73.1 \%$ of the families. ${ }^{23}$ These data corroborate the results found in a Brazilian population study, which indicates the relationship between low family income and the inadequate nutritional status of children under five years of age. 24

We indicate that the positive influence of higher family incomes for complementary feeding may be related to the access to diversified foods such as fruits, vegetables, meat and eggs, as opposed to the food consumption of families with lower purchasing power, which prioritize processed foods and with longer shelf life, in order to meet the needs of the family for a longer period of time.

Complementary feeding did not present statistical significance with the caregiver's schooling. However, those with higher levels of education tend to present a high capability to feed. In Fortaleza, $32.2 \%$ of mothers had less than five years of schooling and presented moderate capability for milk feeding. 13,14 The understanding of the information increases the adequacy of care and decreases the occurrence of malnutrition. 25

The caregivers know basic the health units in their region $(88.9 \%)$, but not all of them access them for child health care $(65.3 \%)$. Among the reasons are the preference for the reference service for HIV treatment $(12.5 \%)$, not having a basic health unit close to their residence $(6.9 \%)$, not liking the assistance at these services (5.6\%) and the unavailability of a pediatrician $(5.2 \%)$.

It is possible to infer that such preference is due to the feeling of familiarity with the specialized HIV service, from the moment of birth to the definition of their diagnosis, to the trust in the professionals of the infectology clinic, confidence in the maintenance of confidentiality of their diagnosis, as well as to the facility to find in the same place supply of medicines and infant formula.

In many cases, caregivers see health services as the main source of support, whether instrumental, emotional or informative, due to the trust in the professionals and the possibility of interacting with other people who are in the same situation. ${ }^{17}$ The professionals' support enables the motivation and the development of skills that positively impact the practices of infant feeding. 27 The assistance to child exposed to HIV in the specialized service should include specific aspects of the clinical condition, and the primary care service should contemplate the promotion of health and other habitual demands of childhood. 28

However, caregivers feel insecure due to the need to reveal their diagnosis to the professionals, and therefore prefer not to attend health services near their home. ${ }^{29}$ There is evidence that both family and specialized service are the main social networks of the caregiver, but this support still falls short of what is needed. 30

In this sense, we recognize that the specialized service, where this research was conducted, provides guidelines that have a positive influence on the health and nutrition of children exposed to HIV, since it has a multi-professional team to assist the population, receives university extension activities and is used as a field of action for the teaching of health professionals.

Therefore, health professionals must recognize the geo-socio-cultural characteristics of the families, in order to adapt the way the guidelines are going to be applied for adequate and healthy nutrition. Permanent education actions are suggested, keeping the professionals who work in health services up-todate, using mainly ministerial manuals and scientific evidence.

This study evidenced a high overall capability to feed, which remained in the milk feeding and decreased in the complementary one. These results point to the need for continuity of guidance and the fundamental role of professionals as promoters of adequate infant feeding. We indicate the need for standardization of guidelines to promote child development, avoiding malnutrition, opportunistic diseases and other nutritional deficiencies, in addition to qualifying health care and bringing research closer to clinical practice.

As limitations of this study, we recognize that the scale used evaluates the care perceived by the family member, and that the application of this instrument in the health service does not allow the observation of practices performed at home, and can overestimate the high capability to prepare and administer milk and complementary feeding. 


\section{Author's contribuitions}

Bick MA and Cardoso de Paula C contributed to the study's conception and design, analysis and interpretation of data, writing of the article, relevant critical review of the intellectual content and final approval of the version to be published. Ceretta PS contributed to the analysis and interpretation of the data and final approval of the version to be published.

\section{References}

1. Brasil. Ministério da Saúde. Secretaria de Vigilância em Saúde. Departamento de Vigilância, Prevenção e Controle das Infecções Sexualmente Transmissíveis, do HIV/Aids e das Hepatites Virais. Boletim Epidemiológico Aids e IST. Brasília; DF, 2017.

2. Brasil. Ministério da Saúde. Secretaria de Vigilância em Saúde. Departamento de Vigilância, Prevenção e Controle das Infecções Sexualmente Transmissíveis, do HIV/Aids e das Hepatites Virais. Protocolo Clínico e Diretrizes Terapêuticas para Manejo da Infecção pelo HIV em Crianças e Adolescentes. Brasília: DF; 2017.

3. Kleinubing RE, Paula CC, Padoin SMM, Silva CB, Ferreira T, Cherubim DO. Care strategies for pregnant women living with HIV: integrative review. Cienc Enferm. 2016; 22 (2) 63-90.

4. Hoffmann IC, Santos WM, Silva CB, Paula CC, Padoin SMM, Barros SMO. Risk factors that interfere on vertical transmission of HIV: integrative review. Enf Obstr. 2014; 1 (1): 31-39

5. Laar AS, Govender V. Individual and Community Perspectives, Attitudes, and Practices to Mother-to-ChildTransmission and Infant Feeding among HIV-Positive Mothers in Sub-Saharan Africa: A Systematic Literature Review. Int J MCH AIDS. 2013; 2 (1): 153-62.

6. Beste S, Essajee S, Siberry G, Hannaford A, Dara J, Sugandhi N, et al. Optimal Antiretroviral Prophylaxis in Infants at High Risk of Acquiring HIV: A Systematic Review. Pediatr Infect Dis J. 2018; 37 (2): 169-175.

7. Cunha AJLA, Leite AJM, Almeida IS. The pediatrician's role in the first thousand days of the child: the pursuit of healthy nutrition and development. J Pediatr. 2015; 91 (Suppl. 1): 44-51.

8. WHO (World Health Organizaton). Guidelines on HIV and infant feeding: principles and recommendations for infant feeding in the context of HIV and summary of evidence. Geneva; 2010.

9. Young S, Wheeler, AC, Mccoy SI, Weiser SD. A review of the role of food insecurity in adherence to care and treatment among adult and pediatric populations living with HIV and AIDS. AIDS Behav. 2014; 18 (Suppl. 5): 505-15.
10. Galvão MTG, Cunha GH, Lima ICV. Women who bear children exposed to human immunodeficiency virus: social representations of motherhood. $\square$ Rev Eletr Enf. 2014; 16 (4): 804-11.

11. Frota MA, Ramos RP, Mourão SJG, Vasconcelos VM, Martins MC, Araújo MAL. Care of child with HIV: carer's perception. Acta Scient Health Sci. 2012; 34 (1): 39-45.

12. Barroso LMM, Freitas JG, Galvão MTG. Scale for assessment of ability to care for children exposed to HIV. Rev Enferm UFPE online. 2013; 7 (1): 722-30.

13. Brandão MN, Souza ES, Brito RJV, Cavalcanti MMSG, Brandão MFR, Cavalvante MC. Challenges in preventing vertical HIV transmission in Petrolina, Pernambuco and Juazeiro, Bahia. Rev Bras Saúde Matern Infant. 2016; 16 (3): 325-36.

14. Brasil. Ministério da Saúde. Secretaria de Atenção à Saúde. Departamento de Atenção Básica. Saúde da Criança: Aleitamento materno e alimentação complementar. $2^{\mathrm{a}}$ ed, $\mathrm{n}^{\mathrm{o}}$ 23. Brasília: DF; 2015.

15. Brasil. Ministério da Saúde. Secretaria de Vigilância em Saúde. Secretaria de Atenção à Saúde. Manual normativo de maternidades da IAHC referência para mulheres HIV positivo e outras que não podem amamentar. Brasília: DF; 2005.

16. Freitas JG, Barroso LMM, Galvão MTG. Maternal ability to take care of children exposed to HIV. Rev Latino-Am Enfermagem. 2013; 21 (4): 1-9.

17. Freitas JG, Cunha GH, Lemos LA, Barroso LMM, Galvão MTG. Feeding of children exposed to the Human Immunodeficiency Virus at birth. Texto Contexto Enferm. 2014; 23 (3): 617-25

18. Alvarenga WA, Galvão MTG, Nascimento LC, Beretta IR, Dupas G. Weakened social network: the experience of caregivers of the HIV-exposed infant. Texto Contexto Enferm. 2015; 24 (3): 775-83

19. Young SL, Israel-Ballard A, Dantzer EA, Ngonyani MM, Nyambo MT, Ash DM, Chantry CJ. Infant feeding practices among HIV-positive women in Dar es Salaam, Tanzania indicate a need for more intensive infant feeding counselling. Public Health Nutr. 2010; 13 (12): 2027-33. 
20. Araújo NL, Lima LHO, Oliveira EAR, Carvalho ES, Duailibe FT, Formiga LMF. Infant feeding and factors related to breastfeeding. Rev Rene online. 2013; 14 (6): 1064-72.

21. Faber M, Benadé AJS. Breast-feeding, complementary feeding and nutritional status of 6-12-month-old infants in rural KwaZulu-Natal. South African J Clin Nutr. 2007; 20 (1): 16-4.

22. Rego SRM, Rego DMS. Association between the usage of alcohol by HIV patients and the adherence to the antiretroviral drug treatment: a literature review. J Bras Psiquiatr. 2010; 59 (1): 70-3

23. Monteiro F, Schmidt ST, Costa IB, Almeida CCB, Matuda NS. Bolsa Família: food and nutrition insecurity of children under five years of age. Ciênc Saúde Coletiva. 2014; 9 (5) 1347-57.

24. Silveira JAC, Colugnati FAB, Poblacion AP, Taddei JAAC Association between socioeconomic and biological factors and infant weight gain: Brazilian Demographic and Health Survey - PNDS-2006/07. J Pediatr. 2015; 91 (3): 284-91.

25. Hasan MT, Magalhaes RJS, Williams GM, Mamun AA. The role of maternal education in the 15-year trajectory of malnutrition in children under 5 years of age in Bangladesh. Matern Child Nutr. 2016; 12 (4): 929-39.
26. Richter LM, Sherr L, Adato M, Belsey M, Chandan U, Desmond C, Drimie S, Haour-Knipe M, Hosegood V, Kimou J, Madhavan S, Mathambo V, Wakhweya A. Strengthening families to support children affected by HIV and AIDS. AIDS Care. 2009; 21 (Suppl. 1): 3-12.

27. Tuthill EL, Butler LM, Pellowski JA, McGrath JM, Cusson RM, Gable RK, et al. Exclusive breast-feeding promotion among HIV-infected women in South Africa: an Information-Motivation-Behavioural Skills model-based pilot intervention. Public Health Nutr. 2017; 20 (8): 148190.

28. Silva GAP, Costa KAO, Giugliani ERJ. Infant feeding: beyond the nutritional aspects. J Pediatr. 2016; 92 (Supl. 1): $2-7$.

29. Alvarenga WA, Dupas G. Experience of taking care of children exposed to HIV: a trajectory of expectations. Rev Latino-Am Enfermagem online. 2014; 22 (5): 848-56.

30. Silva MR, Alvarenga WA, Dupas G. Caregiver experience in preventive treatment for children exposed to Human Immunodeficiency Virus. Rev Rene. 2014; 15 (5): 743-52.

Received on October 16, 2018

Final version presented on July 30, 2019

Approved on August 1, 2019 